\title{
DISCUSSION
}

\section{Three-dimensional modelling of NATM tunnelling in decomposed granite soil}

\author{
J. H. SHIN, D. M. POTTS and L. ZDRAVKOVIC (2002). Géotechnique 52, No. 3, 187-200
}

\section{J. N. Shirlaw, Land Transport Authority, Singapore}

The authors present the results of a very complex threedimensional model of a tunnel in decomposed granite. Further explanation of some of the input parameters and the modelling of the tunnelling process would be useful.

The analysis involves coupled behaviour between the soil and the pore water, so the permeability of the ground must be a key input for the modelling. In Fig. 8, the permeability used is shown as varying with depth from just over $10^{-8} \mathrm{~m} / \mathrm{s}$ to just over $10^{-9} \mathrm{~m} / \mathrm{s}$. The same figure shows the measured values of permeability, with the minimum values generally at about $10^{-7} \mathrm{~m} / \mathrm{s}$. The value bars extend outside the area of the graph. The graph is limited to $10^{-6} \mathrm{~m} / \mathrm{s}$, suggesting that the maximum measured values of permeability were significantly higher than $10^{-6} \mathrm{~m} / \mathrm{s}$. The mass permeability of a weathered rock mass will be governed by the maximum, rather than the minimum, values of permeability measured in discrete tests. The modelling therefore assumes values of permeability that are two to three orders of magnitude lower than those actually measured. For tunnelling below the water table, there is a world of difference between ground with a permeability of $10^{-8} \mathrm{~m} / \mathrm{s}$ and that with $10^{-6} \mathrm{~m} / \mathrm{s}$.

The assumed cohesion at the axis level of the tunnel is about $35 \mathrm{kPa}$, scaling off Fig. 8. The nearest measurements were taken at $17 \mathrm{~m}$ depth. The measured values appear to have been in the range of $5-14 \mathrm{kPa}$, compared with the model input of about $25 \mathrm{kPa}$. Generally, the values used for modelling at tunnel level were at or above the maximum measured values. Howat (1985) showed that completely weathered granite in Hong Kong retained evidence of the original rock structure on a macro scale. He showed that there was a significant difference in strength between the zone near the original joint in the rock and the zone that had, at an earlier stage of weathering, been a corestone boulder. Did the authors consider whether the lower values of cohesion recorded could be related to residual structural features in the weathered rock? If this is the case, it is likely that the response of the rock to excavation would be dominated by the effective strength along the weak planes resulting from these features.

Almost no information is given in the paper on the tunnelling against which the model is validated. I would note that the field data presented are extremely sparse, comprising five surface settlement readings taken close to the line of the tunnel. The points appear to have been read only once, about a month after the tunnel face passed beneath. No piezometer data are presented, so the pore water pressure profiles in Fig. 11 cannot be compared with measured data. There is a major disparity between the effort involved in the modelling and the effort applied to the field measurement used for validation.

However, my main concern is with the relationship between the modelled tunnel and the actual tunnel. Based on Fig. 10 it appears that the full excavation/lining sequence is assumed for a $2 \mathrm{~m}$ length on a daily basis. The model therefore assumes full ring closure within $2 \mathrm{~m}$ of the tunnel face. Ring closure is a critical factor in NATM tunnelling, and it would be unusual for it to be achieved so quickly for such a large tunnel. Could the authors please confirm whether ring closure was actually achieved as modelled?

I am also intrigued by the behaviour of the weathered granite in Seoul. In both Hong Kong and Singapore completely weathered granite behaves as flowing ground if exposed below the water table. Typically, tunnel construction through this grade of weathered granite has been carried out with the use of compressed air, dewatering, grouting or, more recently, pressurised tunnel-boring machines. The paper does not mention the use of any groundwater control measures. Can the authors confirm that no such measures were used, and whether the weathered granite in Seoul is generally stable in a tunnel heading below the water table?

\section{J. L. Knill}

The ground model for this tunnel (Fig. 7), which forms part of the Seoul Subway, is based upon the Moye system of describing granite weathering at the material scale (Moye, 1955). However, it is unclear whether the authors' 'decomposed granite soil' is Moye's 'granitic soil', a (Grade VI) residual soil, or a completely weathered/decomposed granite; each definition is different from the other.

The Moye approach has been overtaken by mass weathering classifications made up of zones characterised by differing proportions of soil and rock. Such classifications are in use within South-East Asia including South Korea (GCO, 1988; Lee \& de Freitas, 1989), and are contained in a Geological Society Engineering Group Working Party Report (Anon, 1995), as well as in BS 5930:1999. The ground models applied in numerical methods of analysis must adopt, at the minimum, standard methods of geotechnical practice. Indeed it could be argued that leading-edge numerical analysis deserves leading-edge ground model construction.

This comment has more than theoretical import. In this case the upper half of the tunnel is located in a weathered rock that can be equated to Moye's 'completely weathered granite' and is below the water table. Such conditions have given rise to face conditions, in tunnels of lesser diameter than that described, that are difficult to control and which arise from the internal erosion of fines from the weathered granite, followed by softening and collapse. I have seen tunnels in completely weathered granite that were in such a state, having a similar overall geometry and hydrogeology to this example. As described by the authors, $2 \mathrm{~m}$ long strips of the tunnel walls were exposed for a 'very short period' to permit support to be introduced. The pore water pressure calculated with tunnel advance (Fig. 11) would suggest that internal erosion could develop, particularly in the invert, where a seam of more weathered granite might be present (Lee \& de Freitas, 1989). Have the authors any explanation as to the factors that allowed the completely weathered granite in this case to be self-supporting under such conditions? 
It is unclear whether the permeability data are based on field or laboratory tests. The permeability test spreads shown in Fig. 8 are not aligned with the thick solid line, which is understood to be 'the average distribution'. The 'average distribution' permeability for 'slightly weathered to unweathered granite' at $40-50 \mathrm{~m}$ depth is in conflict with normal experience. Can these possible anomalies be explained?

\section{Authors' reply}

\section{Permeability}

In the analyses performed in the paper, the permeability, $k$, was assumed to vary with mean effective stress, $p^{\prime}$, according to equation (5), and not specifically with depth. However, in the initial (greenfield) conditions $p^{\prime}$ increases with depth, and therefore so does $k$. During the simulation of tunnel construction in the analysis, $p^{\prime}$ changes and consequently so does the permeability.

Figure 8 compares the variation of the initial permeability in the soil, prior to tunnel construction, with depth used in the analysis with some field data. As the discussers have quite rightly identified, the values used in the analysis are considerably smaller than the field data. The reasons for this are as follows:

(a) Initially, when we began the analysis of the Soul Subway, we used the lower limit value of the field measurements for permeability. However, the analyses resulted in seepage inflows into the tunnel that were considerably larger than those that were recorded in the field. To obtain values consistent with the field measurements of inflow into the tunnel, we had to reduce the permeability values to the order shown in Fig. 8. In essence, we used the field measurements of inflow to back-calculate the field permeability.

(b) The field data presented in Fig. 8 were obtained from conventional borehole piezometer techniques. According to Chandler et al. (1990), who compared the permeability of London Clay obtained using different measurement techniques, the permeability obtained in the field from conventional borehole piezometers was an order of magnitude higher than that obtained using the self-boring permeameter. They identified a number of possible factors to explain this difference, one of which is that the borehole drilling causes the effective stress around a borehole to reduce, thus resulting in an increase in permeability.

It is, of course, well known that permeability is one of the most difficult soil properties to measure with much accuracy.

\section{Cohesion and granites in Seoul}

Weathering of granites in Seoul reduces with depth, without the development of corestones. Consequently, the engineering properties of the in-situ materials vary continuously with depth. Normally, the cohesion intercept increases significantly in the transition zone from the decomposed granite to the weathered granite. However, for numerical modelling, local variations of $c^{\prime}$ were not modelled because one would have to obtain a very detailed spatial site investigation to capture such variations. Instead, a linear variation of the logarithm of $c^{\prime}$ with depth, as presented in Fig. 8, was adopted, which may have resulted in some overestimation of the cohesion at the tunnel spring line.

In general, the granites in Seoul are quite different from those in Hong Kong and Singapore, where the climate is tropical and sub-tropical. It is known that the granite in Seoul is coarse, and has strong inherent bonding (Lee, 1987). It does not flow, even in wet conditions.
Regarding the geological classification, there have been several attempts to quantify the degree of weathering by introducing some quantitative weathering indices. Lee \& de Freitas (1989) indicated that the six-fold system can be generally applicable to the Seoul granite. However, the layer classification in Fig. 7 does not follow any existing system, but is based mainly on the tunnel excavation practice and support pattern in Seoul granite. The ground classification for the tunnel construction in Seoul granite is a simplified and qualitative method, based on values of RMR (rock mass rating) (Lee, 1996).

\section{Field measurements and tunnelling method}

The field measurements used for comparison with the results of the numerical analyses did not form part of the work undertaken during this study. Therefore the instrumentation of the site and data acquisition during tunnel construction were not under the authors' control. The authors have made use of the limited data that were found in the literature and obtained from the Seoul Subway Construction Office. The emphasis on the numerical aspect of the work is also reflected in the title of the paper.

The field settlement data presented in Fig. 17 correspond to the situation in which 3 months have elapsed since the tunnel face passed the measuring array. From the numerical analysis, and from other observations made on site, such a time period is sufficient for steady-state seepage conditions to have developed. Unfortunately, there were no available field piezometer data to compare with the numerical predictions at this measuring site.

The ground conditions and tunnelling method are described in detail in Shin (2000), as indicated in the paper. Tunnel excavation was performed using an upper and a lower bench, and the rate of advancement of the tunnel face was about $2 \mathrm{~m}$ per day, which was evaluated from the average construction speed of the top bench. Both the top and bottom benches were excavated at a similar rate, with the top bench excavated $5 \mathrm{~m}$ ahead of the bottom bench. Shotcrete support was provided immediately after excavation in both benches: consequently there was never any unsupported soil.

Because the modelling of both benches results in a nonaxisymmetric geometry, it cannot be easily accounted for in numerical analysis of the type presented in the paper. This is why we opted for full-face excavation. In the analysis, for each round of excavation an unsupported length of $2 \mathrm{~m}$ of tunnel heading was modelled before support was provided. In the authors' experience the use of bench excavation results in smaller movements than full-face excavation. Consequently, the analysis is potentially likely to overestimate movements because it assumes full-face excavation and an unsupported length of tunnel of $2 \mathrm{~m}$, but to underestimate movements because it assumes full ring closure after only $2 \mathrm{~m}$ of excavation, whereas in the field this occurs after $5 \mathrm{~m}$ when the bottom bench is excavated.

The ground conditions and construction environment in Seoul are not appropriate for the use of normal shield tunnelling techniques, owing to the significant variation of weathering in the soil at the tunnel face. To improve ground conditions and control inflow of groundwater, grouting was extensively adopted.

\section{REFERENCES}

Anon (1995). The description and classification of weathered rocks for engineering purposes; Geological Society Engineering Group Working Party Report. Q. J. Engng Geol. 28, No. 3, 207-242. 
British Standards Institution (1999). Code of practice for site investigations, BS 5930. Milton Keynes: BSI.

Chandler, R. J., Leroueil, S. \& Trenter, N. A. (1990). Measurements of the permeability of London Clay using a self-boring permeameter. Géotechnique 40, No.1, 113-124.

Geotechnical Control Office (1988). Rock and soil descriptions, Geoguide 3. Hong Kong: Civil Engineering Department.

Howat, M. D. (1985). Completely weathered granite: soil or rock? Q. J. Engng Geol., 18, 199-206.

Lee, I. K. (1996). Planning and design of Seoul Subway Line 6. Proc. North American Tunnelling '96 (ed. Ozdemir), Rotterdam: Balkema.
Lee, S. G. \& de Freitas, M. H. (1989). A revision of the description and classification of weathered granite and its application to granites in Korea. Q. J. Engng Geol. 22, No. 1, $31-48$.

Lee, S. G. (1987). Weathering and geotechnical characterisation of Korean granites. $\mathrm{PhD}$ thesis, Imperial College, University of London.

Moye, D. G. (1955). Engineering Geology for the Snowy Mountain Scheme. J. Inst. Engrs Aust. 27, No. 5, 287-298.

Shin, J. H. (2000). Numerical analysis of tunnelling in decomposed granite soil. $\mathrm{PhD}$ thesis, Imperial College, University of London. 